\title{
Inoculação de nutrientes em ovos de matrizes pesadas
}

\author{
Adriana Ayres Pedroso ${ }^{1}$, Leandro Silva Chaves ${ }^{2}$, Karina Ludovico de Almeida Martinez \\ Lopes $^{2}$, Nadja Susana Mogyca Leandro², Marcos Barcellos Café ${ }^{2}$, José Henrique Stringhini ${ }^{2}$ \\ ${ }^{1}$ Bolsista de Pesquisa do CNPq. Departamento de Produção Animal da Escola de Veterinária da Universidade Federal de Goiás, \\ CEP: 74001-970, Goiânia/GO. \\ 2 Departamento de Produção Animal da Escola de Veterinária da Universidade Federal de Goiás, CEP: 74001-970, Goiânia/GO.
}

\begin{abstract}
RESUMO - Foram conduzidos três experimentos para avaliar a influência da inoculação in ovo de ácido linoléico, glicose e glutamina em ovos de matrizes pesadas aos 16 dias de incubação sobre a eclodibilidade e o desempenho dos pintos até 10 dias de idade. O delineamento utilizado foi em blocos ao acaso, com cinco tratamentos, que consistiram da inoculação dos ovos, conforme descrito a seguir: experimento $1-0,100,200$ ou $300 \mu \mathrm{L}$ de ácido linoléico; experimento 2 - 0, 100,200 ou $300 \mathrm{mg}$ de glicose; experimento 3 - 0, 10, 20 ou $30 \mathrm{mg}$ de glutamina. Em todos os experimentos, o grupo controle foi representado por ovos íntegros não inoculados. Na fase pré-eclosão, cada um dos 130 ovos representou uma unidade experimental e, na fase pós-eclosão, cada tratamento contou com quatro repetições de 15 aves. A inoculação de ácido linoléico ou glicose aumentou a mortalidade embrionária, diminuiu a eclodibilidade dos ovos e prejudicou a relação peso do pinto:peso do ovo. Pintos mais leves foram obtidos com a inoculaçãoin ovo de diferentes níveis de ácido linoléico. A inoculaçãoin ovo com ácido linoléico, glicose e glutamina nas concentrações testadas não se mostrou adequada para melhorar características relacionadas à eclodibilidade e ao desempenho de aves até os 10 dias de idade.
\end{abstract}

Palavras-chave: ácido linoléico, desempenho, eclodibilidade, glicose, glutamina, órgãos digestórios

\section{Nutrient inoculation in eggs from heavy breeders}

\begin{abstract}
Three experiments were carried out to evaluate the effects of in ovoinoculat ion of linoleic acid, glucose, and glutamine in chick eggs at $16^{\text {th }}$ day of incubation on hatchability and performance until 10 days of age. It was used a randomized block design with five treatments, as follows: in experiment 1, 0, 100, 200 or $300 \mu \mathrm{L}$ of linoleic acid; in experiment 2, 0,100, 200 or $300 \mathrm{mg}$ of glucose; and in experiment 3, 0, 10, 20 or $30 \mathrm{mg}$ of glutamine. The control was represented by the intact eggs in all experiments. In the pre hatch phase, each one of 130 eggs represented an experimental unit, and in post hatch phase each treatment had four replicates with 15 chicks each. The inoculation of linoleic acid or glucose increased embryo mortality and decreased hatchability and chick weight:egg weight ratio. In ovo inoculation of linoleic acid resulted in lighter chicks. In ovoinoculation of linoleic acid, glucose, and glutamine at different concentrations did not improve bird hatchability and performance until 10 days of age.
\end{abstract}

Key Words: digestory organs, glucose, glutamine, hatchability, linoleic acid, performance

\section{Introdução}

O rápido acesso do pinto ao alimento pode melhorar o desempenho por estimular as enzimas digestivas e o maior desenvolvimento das vilosidades intestinais (Geyra et al., 2001). Uni (2001) demonstrou que, quanto mais cedo a ave é alimentada, maior o desenvolvimento inicial do trato digestório e, portanto, melhor o peso vivo. O acesso do embrião a nutrientes pode melhorar o desenvolvimento do sistema digestório (Foye et al., 2005; Smirnov et al., 2004), a eclodibilidade e o desempenho do frango. Com base nesta premissa, o conceito da suplementação de nutrientes na fase pré-eclosão, ou nutrição in ovo, foi estabelecido.
A nutrição in ovo na fase pré-eclosão é uma prática recente na avicultura. Basicamente, esse processo é feito perfurando-se a casca do ovo embrionado e inoculando-se o nutriente no líquido amniótico por meio de uma seringa (Leitão et al., 2005; Gonzales et al., 2003). A partir do 15으 dia de incubação, o embrião começa a ingerir o líquido amniótico (Klasing, 1998) e, conseqüentemente, assubstâncias presentes também são ingeridas. Além disso, tem-se demonstrado que o embrião possui enzimas digestivas (Sklan et al., 2003) que tornam possível a nutrição na fase pré-eclosão.

Como essa técnica é recente, pouco se sabe acerca dos níveis e tipos de nutrientes que podem ser utilizados na 
nutrição do embrião. Muitas vezes, são omitidos os níveis e a composição dos nutrientes inoculados in ovo (Uni et al., 2003). Uma linha que pode nortear a busca de nutrientes a serem utilizados é o estudo da composição do saco vitelino. O saco vitelino é a fonte primária de nutrição do pinto (Burnham et al., 2001) e contém, estimadamente, $51,7 \%$ de PB, 32,6\% de EE, 4,8\% de cinzas e pequena quantidade de carboidratos (Vieira \& Moran, 1998).

Embora os aminoácidos presentes na gema possam ser suficientes durante o processo de eclosão, após o nascimento, as reservas do saco vitelino da ave são insuficientes para o processo de crescimento (Ohta et al., 2004). A inoculação de aminoácidos já se mostrou viável (Ohta et al., 1999; Johri et al., 2004), melhorando o peso vivo da ave por meio do aumento no conteúdo de aminoácidos do embrião (Ohta et al., 2001) e da gema e da utilização desses aminoácidos pelo embrião (Al-Murrani, 1982). Entre os aminoácidos utilizados para inoculação, a glutamina pode exercer efeitos positivos (Maiorka, 2002), pois apresenta relação positiva entre a síntese protéica e a concentração do aminoácido (Jepson et al., 1988; Welborne, 1995), além de afinidade com o hormônio do crescimento (Ray et al., 2003), cuja síntese se inicia na fase embrionária da ave (Harvey et al., 2001). O saco da gema de um pinto recémeclodido oriundo de uma ave jovem contém aproximadamente $150 \mathrm{mg}$ de glutamina (Vieira \& Moran, 1998).

Os lipídios são a maior fonte de energia do embrião e aproximadamente $35 \%$ do volume inicial em energia é utilizado antes do nascimento (Powell et al., 2004). O ácido linoléico deve estar presente na gema do ovo fértil para que pintos de adequada qualidade sejam produzidos (Gustin, 2002). Latour et al. (1998) estimaram que o embrião pode ter $14 \%$ de ácido linoléico no saco vitelino, o que representa aproximadamente $160 \mathrm{mg}$ no ovo de uma matriz jovem.

Os carboidratos estão presentes em pequenas quantidades na gema (menos que $0,5 \mathrm{~g}$ ) de ovos férteis de matrizes jovens (Vieira \& Moran, 1998) e a gliconeogênese é necessária para o suprimento das necessidades de glicose, principalmente a partir de lipídios provenientes do saco vitelino (Longo, 2004). Provavelmente, o oferecimento de glicose, um monossacarídeo, diminuiria a gliconeogênese ocasionada pelo gasto de energia. Pesquisas recentes têm sugerido que a inoculação de carboidratos em ovos de perus pode ser benéfica para o desenvolvimento do trato gastrintestinal e o aumento da secreção enzimática (Ferket et al., 2005a; Ferket et al., 2005b; Foye et al., 2005). Dissacarídeos como maltose, sucrose e dextrina já se mos- traram benéficos quando inoculados em ovos de matrizes pesadas (Uni et al., 2005).

Neste estudo, foram conduzidos três experimentos com o objetivo de avaliar os efeitos da inoculação in ovo de ácido linoléico, glicose e glutamina aos 16 dias de incubação sobre a mortalidade embrionária, a eclodibilidade e o desempenho dos pintos até os 10 dias de idade.

\section{Material e Métodos}

Em cada experimento, foram utilizados 650 ovos (130 ovos por tratamento) de matrizes Cobb com 35 semanas de idade. Em todos os experimentos, os ovos foram identificados, pesados individualmente e distribuídos em cinco incubadoras reguladas a $37,5^{\circ} \mathrm{C}$ e a $65 \%$ de umidade relativa do ar. As incubadoras, modelo Premium Ecológica, efetuavam a viragem dos ovos em intervalos de duas horas.

Após 16 dias de incubação, os ovos foram higienizados com álcool iodado ( $2 \%$ ) e perfurados na região da câmara de ar com o auxílio de furadeira portátil com broca de $2 \mathrm{~mm}$ de diâmetro evitando perfurar a membrana interna da casca do ovo. Os nutrientes testados foram veiculados em solução salina (Ferket et al., 2005a; Uni et al., 2005) e inoculados no líquido aminiótico utilizando-se uma seringa com agulha 7 x 2,5 mm. Após a inoculação, o orifício da casca foi lacrado com parafina fundida segundo técnica descrita por Gonzales et al. (2003).

No experimento 1 , os tratamentos consistiram da inoculação de ácido linoléico conforme descrito a seguir: controle - ovo mantido com a casca íntegra sem inoculação; 0 AL - inoculação de $300 \mu \mathrm{L}$ de $\mathrm{NaCl}$ a $0,9 \% ; 100 \mathrm{AL}$ $100 \mu \mathrm{L}$ de ácido linoléico (Farmogral $\left.{ }^{1}\right)+200 \mu \mathrm{L}$ de $\mathrm{NaCl}$ a $1,35 \%$ (para que o volume total de $300 \mu \mathrm{L}$ tivesse a concentração de $0,9 \%$ de $\mathrm{NaCl}$ ); $200 \mathrm{AL}$ - 200 $\mu \mathrm{L}$ de ácido linoléico $+100 \mu \mathrm{L}$ de $\mathrm{NaCl}$ a $2,7 \%$ (para que o volume total de $300 \mu \mathrm{L}$ tivesse a concentração de $0,9 \%$ de $\mathrm{NaCl}$ ); e 300 AL - inoculação de $300 \mu \mathrm{L}$ de ácido linoléico.

No experimento 2, realizou-se a inoculação de glicose da seguinte forma: controle - ovos não inoculados; 0 GLI $500 \mu \mathrm{L}$ de $\mathrm{NaCl}$ a $0,9 \% ; 100 \mathrm{GLI}-100 \mathrm{mg}$ de glicose $\left(\mathrm{Merck}^{2}\right)$ diluídos em $500 \mu \mathrm{L}$ de $\mathrm{NaCl}$ a 0,9\%; 200 GLI - 200 mg de glicose diluídos em $500 \mu \mathrm{L}$ de $\mathrm{NaCl}$ a $0,9 \%$; e 300 GLI $300 \mathrm{mg}$ de glicose diluídos em $500 \mu \mathrm{L}$ de $\mathrm{NaCl}$ a $0,9 \%$.

No experimento 3 , os tratamentos consistiram da inoculação de glutamina conforme a seguir: controle - ovos não inoculados; 0 GLU - $200 \mu \mathrm{L}$ de $\mathrm{NaCl}$ a 0,9\%, $10 \mathrm{GLU}$ ovos inoculados com $10 \mathrm{mg}$ de glutamina (Fresenius Kabi3

\footnotetext{
${ }^{1}$ Alameda Coronel Joaquim e Bastos, 132, Marista, Goiânia, GO

${ }^{2}$ Rua Mazzine, 167/173, Cambuci, São Paulo, SP.

${ }^{3}$ Rua Francisco Pereira Coutinho, 347, Parque Taquaral, Campinas, SP.
} 
diluídos em $200 \mu \mathrm{L}$ de $\mathrm{NaCl}$ a 0,9\%; $20 \mathrm{GLU}$ - $20 \mathrm{mg}$ de glutamina diluídos em $200 \mu \mathrm{L}$ de $\mathrm{NaCl}$ a $0,9 \%$; e 30 GLU $30 \mathrm{mg}$ de glutamina diluídos em $200 \mu \mathrm{L}$ de $\mathrm{NaCl}$ a $0,9 \%$.

Após a inoculação, os ovos foram embalados individualmente com sacos de filó e recolocados na incubadora. $\mathrm{Na}$ ocasião do nascimento, os pintos e suas respectivas cascas foram pesados para determinação da perda de peso ao final da incubação. O peso dos pintos foi utilizado para determinação de sua relação com o peso do ovo. Ao final de 22 dias de incubação, os ovos não eclodidos foram abertos e classificados como inférteis, ou o período da mortalidade do embrião foi diagnosticado. A mortalidade embrionária foi classificada em intermediária (16-18 dias), tardia (19 a 21 dias) e pós-bicagem da casca.

A morfometria dos órgãos relacionados ao sistema digestório do neonato foi feita para avaliar a possível relação entre os nutrientes fornecidos in ovo e o desenvolvimento do sistema no momento da eclosão dos pintos. No momento do nascimento, oito pintos machos por tratamento foram sacrificados para realização da biometria dos órgãos do sistema digestório e do saco vitelino e determinação da densidade do intestino delgado, conforme descrito por Longo (2004).

Em cada experimento, 60 pintos machos por tratamento, 15 por repetição, foram alojados em baterias metálicas aquecidas para avaliação do desempenho zootécnico. Foi fornecida dieta pré-inicial farelada à base de milho e soja, formulada com base nas recomendações de Rostagno et al. (2000), com $2.950 \mathrm{kcal}$ de EM/kg e 22\% de PB, e água à vontade. O consumo de ração, o peso vivo e a conversão alimentar foram avaliados até os 10 dias de idade.

O delineamento utilizado foi em blocos ao acaso, com cinco tratamentos. Na fase pré-eclosão, foram dispostos 130 ovos (unidades experimentos) em cada tratamento, adotando-se o fator bloco para eliminar o efeito da incuba- dora. Na fase pós-eclosão, utilizaram-se quatro repetições de 15 aves por tratamento, adotando-se o fator bloco para eliminar o efeito do sexo.

Os dados quantitativos foram analisados por meio do PROC GLM e comparados pelo teste Tukey. Os dados qualitativos, por sua vez, foram analisados pelo PROC FREQ e comparados pelo teste qui quadrado no SAS (1998).

\section{Resultados e Discussão}

No Experimento 1, a mortalidade embrionária foi maior na fase tardia $(\mathrm{P}<0,01)$, comprovando que os embriões toleraram o processo de inoculação do ácido linoléico aos 16 dias de incubação e nas 48 horas seguintes, mas, na fase tardia de incubação, quando o nutriente deveria ser completamente consumido, pereceram (Tabela 1).

As mais altas porcentagens de mortalidade foram observadas com a inoculação de 100 e 200 mg de ácido linoléico $(\mathrm{P}<0,04)$, mas, ao contrário do esperado, o nível de $300 \mathrm{mg}$ ocasionou mortalidade embrionária semelhante aos tratamentos controle e inoculado com placebo. Esse efeito pode ser atribuído ao fato de que os tratamentos $100 \mathrm{AL}$ e 200 AL, além da inoculação com lipídio, sofreram inoculação de 200 e $100 \mu \mathrm{L}$ de solução salina, respectivamente. Não houve efeito da interação nível de ácido linoléico inoculado $\times$ período de mortalidade.

No experimento 2, a inoculação de $0,5 \mathrm{~mL}$ de solução salina nos ovos do tratamento 0 GLI provocou maior mortalidade na fase pré-eclosão em relação ao tratamento controle, no qual o ovo permaneceu íntegro ( $\mathrm{P}<0,05$, Tabela 2). Provavelmente o volume inoculado foi excessivo, culminando no óbito do embrião.

A inoculação de glicose também ocasionou maior mortalidade em relação ao tratamento 0 GLI. Possivelmente, a

Tabela 1 - Porcentagem de mortalidade de embriões nos tratamentos com inoculação de ácido linoléico (experimento 1) Table 1 - Mortality porcentage of embryos from in ovo inoculation with linoleic acid according to embryo age (experiment 1)

\begin{tabular}{|c|c|c|c|c|c|c|}
\hline \multirow[b]{2}{*}{$\begin{array}{l}\text { Período da mortalidade } \\
\text { Mortality phase }\end{array}$} & \multicolumn{5}{|c|}{$\begin{array}{c}\text { Tratamento } \\
\text { Treatment }\end{array}$} & \multirow[b]{2}{*}{ Total } \\
\hline & $\begin{array}{l}\text { Controle } \\
\text { Control }\end{array}$ & $0 \mathrm{AL}$ & $100 \mathrm{AL}$ & $200 \mathrm{AL}$ & $300 \mathrm{AL}$ & \\
\hline $\begin{array}{l}\text { Intermediária ( } 16 \text { a } 18 \text { dias) } \\
\text { Intermediary (16 to } 18 \text { days) }\end{array}$ & 1,18 & 0,00 & 4,71 & 5,29 & 1,18 & 12,35 \\
\hline $\begin{array}{l}\text { Tardia (19 a } 21 \text { dias }) \\
\text { Late (19 to } 21 \text { days) }\end{array}$ & 4,12 & 6,47 & 18,24 & 12,94 & 7,06 & 56,48 \\
\hline $\begin{array}{l}\text { After breaking } \\
\text { Total }\end{array}$ & 14,12 & 15,88 & 28,24 & 28,23 & 13,53 & 100,00 \\
\hline
\end{tabular}


Tabela 2 - Porcentagem de mortalidade de embriões nos tratamentos com inoculação de glicose (experimento 2) Table 2 - Mortality porcentage of embryos from in ovo inoculation with glucose according to embryo age (experiment 2)

\begin{tabular}{|c|c|c|c|c|c|c|}
\hline \multirow[b]{2}{*}{$\begin{array}{l}\text { Período da mortalidade } \\
\text { Mortality phase }\end{array}$} & \multicolumn{5}{|c|}{$\begin{array}{c}\text { Tratamento } \\
\text { Treatment }\end{array}$} & \multirow[b]{2}{*}{ Total } \\
\hline & $\begin{array}{l}\text { Controle } \\
\text { Control }\end{array}$ & 0 GLI & $100 \mathrm{GLI}$ & $200 \mathrm{GLI}$ & $300 \mathrm{GLI}$ & \\
\hline $\begin{array}{l}\text { Intermediária ( } 16 \text { a } 18 \text { dias) } \\
\text { Intermediary (16 to } 18 \text { days) }\end{array}$ & 0,99 & 6,84 & 20,14 & 18,07 & 20,59 & 66,62 \\
\hline Tardia (19 a 21 dias) & 3,45 & 2,44 & 3,02 & 3,42 & 5,27 & 17,60 \\
\hline Total & 7,40 & 11,72 & 28,19 & 25,40 & 27,29 & 100,00 \\
\hline
\end{tabular}

glicose nas concentrações testadas promoveu um desequilíbrio osmótico que resultou na morte do embrião pouco tempo após a inoculação do nutriente, pois foi observada maior freqüência da mortalidade intermediária $(\mathrm{P}<0,06)$. Em trabalho recente, Ferket et al. (2005b) recomendaram que a osmolaridade de soluções nutritivas a serem utilizadas in ovo, à base de carboidratos, seja mantida entre 400 e $600 \mathrm{mOsm}$. Neste experimento, as osmolaridades das soluções inoculados foram 1.264, 2.375 e 3.486 mOsm, níveis bem acima dos recomendados, quando utilizados 100, 200 e $300 \mathrm{mg}$ de glicose, respectivamente, o que pode ter ocasionado maior mortalidade embrionária. Entretanto, o planejamento e a execução deste experimento foram anteriores à publicação dos dados de Ferket et al. (2005b).

Ipek et al. (2004), ao inocularem baixos níveis de glicose (5, 10 e $15 \mathrm{mg})$, não observaram aumento na mortalidade embrionária nem melhora no desempenho dos pintos, entretanto, os baixos níveis de glicose não contribuiriam como suplemento energético para a ave. A partir dos dados reportados por Longo et al. (2005), verificou-se que os níveis de 100, 200 e $300 \mathrm{mg}$ de glicose fornecem respectivamente 0,34,0,69 e 1,02 kcal de EM, quantidade insuficiente para o processo de rompimento das membranas interna e externa da casca do ovo.

A inoculação de glutamina não afetou a mortalidade embrionária em relação ao grupo controle (Tabela 3), provavelmente em virtude do menor volume inoculado em relação aos outros experimentos. São escassos os trabalhos relativos à inoculação de nutrientes in ovo (Ohta \& Kidd, 2001), mas, trabalhando com ovos grandes (68-70 g), Ingran et al. (1997) não observaram aumento na mortalidade embrionária com a inoculação de $0,5 \mathrm{~mL}$. Uni et al. (2005) descreveram que a inoculação de $1 \mathrm{~mL}$ em ovos provenientes de matrizes com 39 semanas de idade (cinco semanas mais velhas que as utilizadas nessa pesquisa) não afetou a eclodibilidade dos ovos. Provavelmente, há uma relação entre o tamanho do ovo utilizado e o volume inoculado, indicando que mais pesquisas devem ser desenvolvidas.

No experimento 1 (Tabela 4), a menor quantidade de óleo fornecida in ovo (tratamento $100 \mathrm{AL}$ ) resultou em menor eclodibilidade e peso do pinto em relação aos dos tratamento controle. A porcentagem de perda de peso foi maior no tratamento $100 \mathrm{AL}$ em comparação ao tratamento controle e 0 AL. O prejuízo observado no desenvolvimento da ave no terço final de incubação pode estar relacionado à combinação do lipídio com a solução salina, pois o ácido linoléico pode ter permanecido disperso no líquido amniótico, que, provavelmente, não foi completamente ingerido. Sabe-se que embriões possuem capacidade limitada de digerir lipídios provenientes do saco da gema na fase pré-eclosão (Noy \& Sklan, 1998), todavia, não foram obtidos dados na literatura sobre o uso de ácido linoléico in ovo. Neste experimento, a mistura inoculada pode ter sido prejudicial para a capacidade limitada de hidrólise do trato intestinal da ave. Os tratamentos com diferentes concentrações de ácido linoléico (100, 200 e 300 AL) também produziram animais mais leves que o tratamento controle.

No experimento 2, a eclodibilidade dos ovos inoculados com glicose foi baixa em relação ao tratamento controle (Tabela 5). Como citado anteriormente, provavelmente a osmolaridade das soluções conduziu à baixa eclodibilidade observada nos tratamentos com inoculação de glicose. A pequena quantidade de energia fornecida pela quantidade de glicose inoculada pode não ter sido benéfica para os demais parâmetros avaliados, como perda de peso ao final da incubação, porcentagem de peso do pinto em relação ao peso do ovo e peso do pinto. Resultados de pesquisas recentes sugerem que a inoculação de dissacarídeos in ovo, em vez de monossacarídeos como a glicose, pode ser benéfica, pois estimula a secreção enzimática (Foye et al., 2005; Ferket et al., 2005a). 
Tabela 3 - Porcentagem de mortalidade de embriões nos tratamentos com inoculação de glutamina (experimento 3) Table 3 - Mortality porcentage of embryos from in ovo inoculation with glutamine according to embryo age (experiment 3)

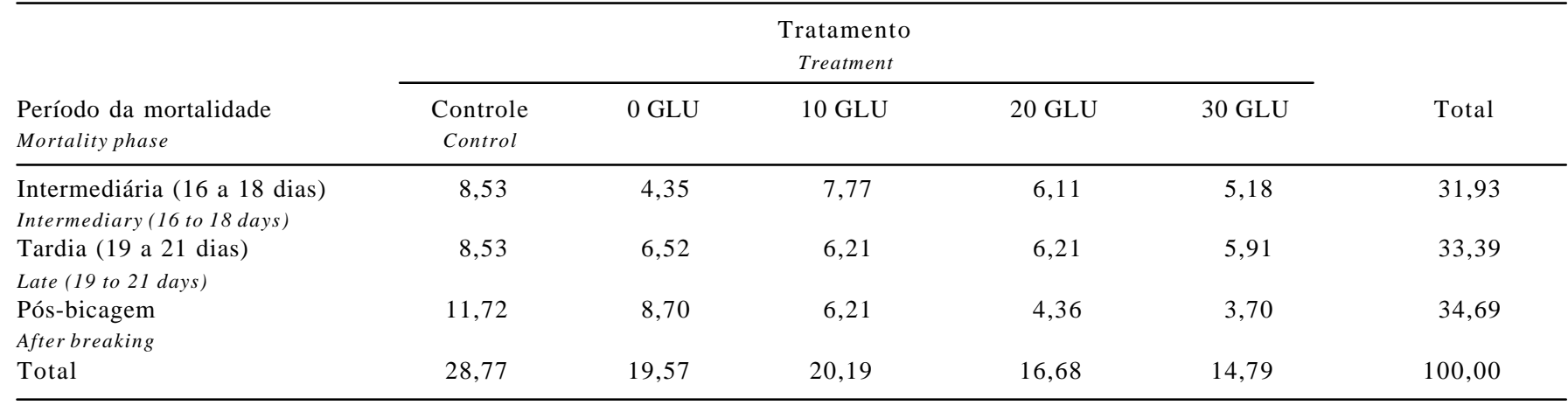

Tabela 4 - Eclodibilidade dos ovos (ECLO), perda de peso do ovo ao final da incubação (PP), peso dos pintos no momento da eclosão em relação ao peso do ovo (PINT) e peso das aves (PA) nos tratamentos com inoculação de ácido linoléico in ovo (experimento 1)

Table 4 - Egg hatchability (ECLO), egg weight loss at the end of incubation (PP), chick weight at hatching moment in relation to egg weight (PINT) and chick weight (PA) from in ovo inoculation with linoleic acid (experiment 1)

\begin{tabular}{lrrrr}
\hline & ECLO $(\%)$ & PP $(\%)$ & PINT $(\%)$ & PA $(\mathrm{g})$ \\
\hline Controle & $65,63 \mathrm{a}$ & $15,32 \mathrm{~b}$ & $75,00 \mathrm{a}$ & $41,3 \mathrm{a}$ \\
Control & & & & \\
$0 \mathrm{AL}$ & $44,93 \mathrm{ab}$ & $15,60 \mathrm{~b}$ & $74,82 \mathrm{ab}$ & $39,8 \mathrm{ab}$ \\
$100 \mathrm{AL}$ & $17,71 \mathrm{~b}$ & $17,11 \mathrm{a}$ & $73,46 \mathrm{~b}$ & $38,5 \mathrm{~b}$ \\
$200 \mathrm{AL}$ & $25,00 \mathrm{ab}$ & $16,04 \mathrm{ab}$ & $74,05 \mathrm{ab}$ & $37,8 \mathrm{~b}$ \\
$300 \mathrm{AL}$ & $54,17 \mathrm{ab}$ & $16,73 \mathrm{ab}$ & $73,69 \mathrm{ab}$ & $38,8 \mathrm{~b}$ \\
$\mathrm{CV}(\%)$ & 49,49 & 18,28 & 3,04 & 2,76 \\
\hline
\end{tabular}

a, b Médias seguidas de letras distintas diferem $(P<0,03)$ pelo teste Tukey. $a, b$ Means followed by different letters differ $(P<0.03)$ by Tukey test.

Tabela 5 - Eclodibilidade dos ovos (ECLO), perda de peso do ovo ao final da incubação (PP), peso dos pintos no momento da eclosão em relação ao peso do ovo (PINT) e peso das aves (PA) nos tratamentos com inoculação de glicose in ovo (experimento 2)

Table 5 - Egg hatchability (ECLO), egg weight loss at the end of incubation (PP), chick weight at hatching moment in relation to egg weight (PINT) and chick weight (PA) from in ovo inoculation with glucose (experiment 2)

\begin{tabular}{lcccc}
\hline & ECLO $(\%)$ & PP $(\%)$ & PINT $(\%)$ & PA $(\mathrm{g})$ \\
\hline Controle & $67,75 \mathrm{a}$ & $17,07 \mathrm{a}$ & $73,44 \mathrm{a}$ & $40,7 \mathrm{a}$ \\
Control & & & & \\
0 GLI & $55,75 \mathrm{ab}$ & $16,65 \mathrm{a}$ & $74,01 \mathrm{a}$ & $41,2 \mathrm{a}$ \\
$100 \mathrm{GLI}$ & $25,50 \mathrm{c}$ & $16,22 \mathrm{a}$ & $74,67 \mathrm{a}$ & $41,2 \mathrm{a}$ \\
$200 \mathrm{GLI}$ & $40,00 \mathrm{bc}$ & $16,57 \mathrm{a}$ & $74,42 \mathrm{a}$ & $39,1 \mathrm{a}$ \\
$300 \mathrm{GLI}$ & $29,75 \mathrm{c}$ & $16,82 \mathrm{a}$ & $73,96 \mathrm{a}$ & $40,6 \mathrm{a}$ \\
CV $(\%)$ & 27,16 & 20,40 & 4,25 & 3,06 \\
\hline
\end{tabular}

a, c Médias seguidas de letras distintas diferem $(P<0,01)$ pelo teste Tukey. a, $c$ Means followed by different letters differ $(P<0.01)$ by Tukey test.
Tabela 6 - Eclodibilidade dos ovos (ECLO), perda de peso do ovo ao final da incubação (PP), peso dos pintos no momento da eclosão em relação ao peso do ovo (PINT) e peso das aves (PA) nos tratamentos com inoculação de glutamina in ovo (experimento 3)

Table 6 - Egg hatchability (ECLO), egg weight loss at the end of incubation (PP), chick weight at hatching moment in relation to egg weight (PINT) and chick weight (PA) from in ovo inoculation with glutamine (experiment 3 )

\begin{tabular}{lcccc}
\hline & ECLO $(\%)$ & PP $(\%)$ & PINT $(\%)$ & PA $(\mathrm{g})$ \\
\hline Controle & $71,00 \mathrm{a}$ & $11,40 \mathrm{a}$ & $73,29 \mathrm{a}$ & $45,3 \mathrm{a}$ \\
Control & & & & \\
$0 \mathrm{GLU}$ & $6,52 \mathrm{a}$ & $11,48 \mathrm{a}$ & $72,99 \mathrm{a}$ & $45,4 \mathrm{a}$ \\
$10 \mathrm{GLU}$ & $74,64 \mathrm{a}$ & $11,23 \mathrm{a}$ & $73,28 \mathrm{a}$ & $43,0 \mathrm{a}$ \\
$20 \mathrm{GLU}$ & $78,08 \mathrm{a}$ & $11,91 \mathrm{a}$ & $72,59 \mathrm{a}$ & $44,4 \mathrm{a}$ \\
30 GLU & $75,71 \mathrm{a}$ & $11,55 \mathrm{a}$ & $72,50 \mathrm{a}$ & $44,7 \mathrm{a}$ \\
CV $(\%)$ & 11,69 & 19,31 & 5,67 & 3,27 \\
\hline
\end{tabular}

A inoculação com glutamina, independentemente do nível, não ocasionou qualquer benefício sobre a eclodibilidade, a perda de peso ao final da incubação, o peso do pinto em relação ao peso do ovo e o peso absoluto da ave ao nascimento (Tabela 6). Ohta et al. (2001), inoculando uma mistura de aminoácidos in ovo contendo $6,99 \mathrm{mg}$ de glutamina aos sete dias de incubação, observaram melhora na relação do peso do pinto em relação ao peso do ovo. Uma mistura de aminoácidos oferecida precocemente talvez fosse mais benéfica às características avaliadas que o fornecimento de um único aminoácido. Sabe-se que pode haver prejuízo no desempenho animal, caso um aminoácido seja fornecido em desequilíbrio aos demais (D’Mello, 2003). Além disso, a época do fornecimento do aminoácido in ovo parece ser fundamental, visto que os aminoácidos são responsáveis pela formação dos tecidos durante a embriogênese (Campos, 2003). O fornecimento de aminoácidos in ovo nos estádios precoce ou intermediário de desenvolvimento do embrião deve ser pesquisado. 
Tabela 7 - Pesos do saco vitelino (SG), fígado (FG), pâncreas (PA), esôfago + papo (EP), proventrículo + moela (PM), intestino delgado (ID) e intestino grosso (IG), comprimento do intestino delgado (CID) e densidade do intestino delgado (DD) dos pintos neonatos nos tratamentos com inoculação de ácido linoléico in ovo (experimento 1)

Table 7 - Weights of viteline sac (SV), liver (FG), pancreas (PA), esophagus + crop (EP), proventriculus + gizzard (PM), small intestine (ID), and large intestine (IG), small intestine length (CID) and small intestine density (DD) of chicks from in ovo inoculation with linoleic acid (experiment 1)

\begin{tabular}{|c|c|c|c|c|c|c|c|c|c|}
\hline & $\mathrm{SV}(\mathrm{g})$ & $\mathrm{FG}(\mathrm{g})$ & PA (g) & $\mathrm{EP}(\mathrm{g})$ & PM (g) & ID $(g)$ & $\mathrm{IG}(\mathrm{g})$ & $\mathrm{CID}(\mathrm{cm})$ & $\mathrm{DD}(\mathrm{mg} / \mathrm{cm})$ \\
\hline Controle & 7,03 & 1,20 & 0,05 & 0,57 & 2,54 & 0,99 & 0,58 & 33,25 & 27,83 \\
\hline Control & & & & & & & & & \\
\hline $0 \mathrm{AL}$ & 6,51 & 1,20 & 0,04 & 0,50 & 2,61 & 1,02 & 0,50 & 29,00 & 30,75 \\
\hline $100 \mathrm{AL}$ & 5,94 & 1,18 & 0,05 & 0,47 & 2,51 & 1,06 & 0,47 & 31,50 & 33,05 \\
\hline $200 \mathrm{AL}$ & 5,39 & 1,21 & 0,05 & 0,48 & 2,76 & 1,04 & 0,42 & 32,75 & 34,99 \\
\hline $300 \mathrm{AL}$ & 5,47 & 1,08 & 0,05 & 0,60 & 2,87 & 1,12 & 0,48 & 33,75 & 32,79 \\
\hline $\mathrm{CV}(\%)$ & 25,54 & 16,24 & 23,16 & 22,80 & 15,10 & 28,28 & 44,72 & 13,21 & 24,83 \\
\hline
\end{tabular}

Tabela 8 - Pesos do saco vitelino (SV), fígado (FG), pâncreas (PA), do esôfago + papo (EP), proventrículo + moela (PM), intestino delgado (ID) e intestino grosso (IG), comprimento do intestino delgado (CID) e densidade do intestino delgado (DD) dos pintos recémeclodidos nos tratamentos com inoculação de glicose in ovo (experimento 2)

Table 8 - Weights of viteline sac (SV), liver (FG), pancreas (PA), esophagus + crop (EP), proventriculus + gizzard (PM), small intestine (ID), large intestine $(I G)$, small intestine length (CID) and small intestine density (DD) of chicks from in ovo inoculation with glucose (experiment 2)

\begin{tabular}{lccccccccc}
\hline & $\mathrm{SG}(\mathrm{g})$ & $\mathrm{FG}(\mathrm{g})$ & $\mathrm{PA}(\mathrm{g})$ & $\mathrm{EP}(\mathrm{g})$ & $\mathrm{PM}(\mathrm{g})$ & $\mathrm{ID}(\mathrm{g})$ & $\mathrm{IG}(\mathrm{g})$ & $\mathrm{CID}(\mathrm{cm})$ & $\mathrm{DD}(\mathrm{mg} / \mathrm{cm})$ \\
\hline Controle & 9,13 & 0,97 & 0,03 & 0,57 & 2,33 & 0,79 & 0,36 & 30,50 & 26,46 \\
Control & & & & & & & & \\
0 GLI & 7,13 & 0,99 & 0,05 & 0,48 & 2,45 & 0,84 & 0,42 & 29,75 \\
100 GLI & 6,82 & 1,04 & 0,05 & 0,53 & 2,58 & 0,98 & 0,55 & 30,37 & 32,08 \\
200 GLI & 6,97 & 1,00 & 0,04 & 0,57 & 2,29 & 0,87 & 0,36 & 29,37 & 29,75 \\
300 GLI & 7,15 & 0,94 & 0,03 & 0,49 & 2,37 & 0,83 & 0,35 & 26,50 \\
CV $(\%)$ & 19,57 & 10,08 & 40,86 & 18,50 & 16,12 & 20,35 & 36,33 & 10,56 & 16,32 \\
\hline
\end{tabular}

Tabela 9 - Pesos do saco vitelino (SV), do fígado (FG), do pâncreas (PA), do esôfago + papo (EP), do proventrículo + moela (PM), do intestino delgado (ID) e do intestino grosso (IG), comprimento do intestino delgado (CID) e densidade do intestino delgado (DD) dos pintos recém-eclodidos nos tratamentos com inoculação de glutamina in ovo (experimento 3 )

Table 9 - Weights of viteline sac (SV), liver (FG), pancreas (PA), esophagus + crop (EP), proventriculus + gizzard (PM), small intestine (ID), large intestine (IG), small intestine length (CID) and small intestine density (DD) of chicks from in ovo inoculation with glutamine (experiment 3 )

\begin{tabular}{|c|c|c|c|c|c|c|c|c|c|}
\hline & $\mathrm{SV}(\mathrm{g})$ & $\mathrm{FG}(\mathrm{g})$ & PA (g) & $\mathrm{EP}(\mathrm{g})$ & $\mathrm{PM}(\mathrm{g})$ & ID $(g)$ & IG (g) & CID $(\mathrm{cm})$ & $\mathrm{DD}(\mathrm{mg} / \mathrm{cm})$ \\
\hline $\begin{array}{l}\text { Controle } \\
\text { Control }\end{array}$ & 6,35 & 1,19 & 0,05 & 0,48 & 2,56 & 0,84 & 0,52 & 28,37 & 30,02 \\
\hline $0 \mathrm{GLU}$ & 7,79 & 1,19 & 0,04 & 0,53 & 2,65 & 1,03 & 0,44 & 31,87 & 32,52 \\
\hline $20 \mathrm{GLU}$ & 6,40 & 1,21 & 0,05 & 0,58 & 2,59 & 1,04 & 0,44 & 30,62 & 34,04 \\
\hline 30 GLU & 6,47 & 1,04 & 0,04 & 0,53 & 2,67 & 1,08 & 0,42 & 31,87 & 33,65 \\
\hline $\mathrm{CV}(\%)$ & 29,43 & 15,56 & 34,80 & 21,90 & 13,35 & 24,50 & 40,54 & 12,16 & 19,83 \\
\hline
\end{tabular}

a Médias seguidas de letras iguais não diferem $(P>0,05)$ pelo teste Tukey.

${ }^{a}$ Means followed by common letters do not differ $(P>0.05)$ by Tukey test.

Não houve qualquer relação entre a biometria dos órgãos e o nutriente oferecido na fase pré-eclosão em todos os experimentos (Tabelas 7 a 9). O número de pintos amostrados e o alto coeficiente de variação encontrado podem estar relacionados à ausência de resultados significativos na característica analisada.

No experimento 1 não foi observado qualquer efeito do ácido linoléico sobre a morfometria intestinal. Nenhuma modificação foi observada no saco da gema, embora já esteja estabelecido que a mobilização do con- teúdo de lipídios do saco da gema para o intestino pelo divertículo de Meckel inicia na fase pré-eclosão e varia em função dos nutrientes contidos no ovo (Noy \& Sklan, 1998). É sabido também que o maior desenvolvimento dos órgãos na fase pós-eclosão pode indicar maior necessidade de enzimas para metabolização do lipídio ingerido (Corless \& Sell, 1999), visto que a gordura precisa ser emulsificada com enzimas pancreáticas e sais biliares, resultando em maior desenvolvimento do fígado e do pâncreas. 
Tabela 10 - Peso vivo (PV), consumo de ração (CR) e conversão alimentar (CA) dos pintos dos tratamentos com inoculação de ácido linoléico in ovo(experimento 1) aos 10 dias de idade

Table 10 - Body weight (BW), feed intake (FI) and feed to gain ratio $(F / G)$ of chicks at 10 days of age from in ovo inoculationwith linoleic acid (experiment 1)

\begin{tabular}{lccc}
\hline & $\mathrm{PV}(\mathrm{g})$ & $\mathrm{CR}(\mathrm{g})$ & $\mathrm{CA}(\mathrm{g} / \mathrm{g})$ \\
& $B W$ & $F I$ & $F / G$ \\
\hline Controle & 271,8 & 270,4 & 0,87 \\
Control & & & \\
$0 \mathrm{AL}$ & 265,7 & 281,4 & 0,82 \\
$100 \mathrm{AL}$ & 280,0 & 272,1 & 0,91 \\
$200 \mathrm{AL}$ & 262,8 & 262,1 & 0,86 \\
$300 \mathrm{AL}$ & 262,0 & 261,2 & 0,88 \\
$\mathrm{CV}(\%)$ & 9,25 & 6,22 & 8,25 \\
\hline
\end{tabular}

Tem-se relatado que o fornecimento de carboidratos complexos in ovo pode refletir em modificações microscópicas no intestino delgado e no fígado, em relação ao conteúdo de glicogênio do órgão (Uni et al., 2005). O mecanismo da absorção intestinal da glicose, um carboidrato simples, não exige atividade enzimática (Longo et al., 2005) e talvez este fato tenha propiciado a ausência de diferenças na biometria intestinal entre os tratamentos pesquisados.

A inoculação de glutamina foi efetuada tendo em vista os benefícios que o aminoácido oferece, como a manutenção e o reparo da mucosa do intestino quando oferecida via oral ou parenteral (Maiorka, 2002; Ajinomoto, 2004; Matarese et al., 2004). Entretanto, nenhuma modificação na morfometria do intestino delgado e grosso foi observada no experimento 3 .

A fonte de lipídio oferecida in ovo não promoveu melhoras no peso vivo, no consumo de ração e na conversão alimentar até os 10 dias de idade (Tabela 10). Não foram observadas alterações na economia de reservas na fase pré-eclosão ou durante a eclosão que pudessem refletir em melhor desempenho ao final de dez dias.

A inoculação de glicose não melhorou no desempenho das aves (Tabela 11). Uni et al. (2005), utilizando $250 \mathrm{mg}$ de carboidratos in ovo (maltose, sacarose e dextrina), observaram melhora no peso da ave na fase pré-eclosão e aos 10 dias de idade e atribuíram este fato à reserva de glicogênio hepático obtida pela inoculação dos nutrientes. Provavelmente, a utilização de dissacarídeos, em vez de um monossacarídeo como a glicose, tenha propiciado diferenças significativas no desempenho das aves.

Apesar dos relatos de efeitos positivos da inoculação de aminoácidos in ovo (Al-Murrani, 1982; Ohta et al., 1999; Ohta et al., 2001; Johri et al., 2004), neste estudo, não foram constatados efeitos positivos da inoculação de glutamina sobre os parâmetros de desempenho anali-
Tabela 11 - Peso vivo (PV), consumo de ração (CR) e conversão alimentar dos pintos dos tratamentos com inoculação de glicose in ovo(experimento 2) aos 10 dias de idade

Table 11 - Body weight (BW), feed intake (FI) and feed to gain ratio $(F / G)$ of chicks at 10 days of age from in ovo inoculationwith glucose (Experiment 2)

\begin{tabular}{lccc}
\hline & PV $(\mathrm{g})$ & $\mathrm{CR}(\mathrm{g})$ & $\mathrm{CA}(\mathrm{g} / \mathrm{g})$ \\
& $B W$ & $F I$ & $F / G$ \\
\hline Controle & 278,2 & 222,6 & 0,93 \\
Control & & & \\
0 GLI & 266,7 & 213,3 & 0,94 \\
100 GLI & 271,7 & 226,6 & 0,98 \\
200 GLI & 284,5 & 232,0 & 0,94 \\
300 GLI & 276,2 & 225,1 & 0,95 \\
CV $(\%)$ & 4,50 & 6,13 & 4,23 \\
\hline
\end{tabular}

Tabela 12 - Peso vivo (PV), consumo de ração (CR) e conversão alimentar dos pintos dos tratamentos com inoculação de glutamina in ovo (experimento 3 ) aos 10 dias de idade

Table 12 - Body weight (BW), feed intake (FI) and feed to gain ratio (F/G) of chicks at 10 days of age from in ovo inoculation with glutamine (experiment 3 )

\begin{tabular}{lccc}
\hline & $\begin{array}{c}\text { PV }(\mathrm{g}) \\
B W\end{array}$ & $\begin{array}{c}\text { CR }(\mathrm{g}) \\
F I\end{array}$ & $\begin{array}{c}\text { CA }(\mathrm{g} / \mathrm{g}) \\
F / G\end{array}$ \\
\hline Controle & $283,9 \mathrm{a}$ & $281,1 \mathrm{a}$ & $1,17 \mathrm{a}$ \\
Control & & & \\
$0 \mathrm{GLU}$ & $261,7 \mathrm{~b}$ & $263,4 \mathrm{a}$ & $1,21 \mathrm{a}$ \\
$10 \mathrm{GLU}$ & $269,5 \mathrm{ab}$ & $266,6 \mathrm{a}$ & $1,17 \mathrm{a}$ \\
$20 \mathrm{GLU}$ & $278,5 \mathrm{ab}$ & $278,5 \mathrm{a}$ & $1,18 \mathrm{a}$ \\
30 GLU & $279,8 \mathrm{ab}$ & $281,8 \mathrm{a}$ & $1,19 \mathrm{a}$ \\
CV $(\%)$ & 3,08 & 3,29 & 3,53 \\
\hline
\end{tabular}

a, c Médias seguidas de letras distintas diferem $(P<0,05)$ pelo teste Tukey. a, $c$ Means followed by different letters differ $(P<0.05)$ by Tukey test.

sados. Ao contrário, foram observados prejuízos no peso vivo dos pintos no tratamento 0 GLU em relação ao controle. Resultado similar foi obtido por Gomide Jr. et al. (2003), que observaram prejuízos nos tratamentos com solução placebo e atribuíram este efeito à menor densidade dos vilos no trato intestinal.

\section{Conclusões}

A inoculação in ovo de ácido linoléico, glicose ou glutamina foi prejudicial para as características relacionadas à eclodibilidade e ao desempenho dos pintos até 10 dias de idade.

\section{Agradecimento}

Ao Conselho Nacional de Desenvolvimento Científico e Tecnológico - CNPq, pelos recursos fornecidos. À Fresenius Kabi, pela doação da glutamina, e à Perdigão Agroindustrial, pela doação dos ovos. 


\section{Literatura Citada}

AJimonomoto. Glutamina. Disponível em: http:<www.ajinomoto.com.br> Acesso em: 27/08/2004.

AL-MURRANI, W.K. Effect of injecting amino acids into the egg on embryonic and subsequent growth in the domestic fowl. British Poultry Science, v.23, n.2, p.171-174, 1982.

BURNHAM, M.R.; PEEBLES, E.D.; GARDNER, C.W. et al. Effects of incubator humidity and hen age on yolk composition in broiler hatching eggs from young breeders. Poultry Science, v. 80 , n. 10 , p.1444-1450, 2001.

CAMPOS, E.J. Nutrição da matriz e do embrião. In: MACARI, M.; GONZALES, E. (Eds). Manejo da incubação. Campinas: Fundação APINCO de Ciência e Tecnologia Avícolas, 2003. p.455-468.

CORLESS, A.B.; SELL, J.L. The effects of delayed acess to feed and water on the physical and functional development of the digestive system of young turkeys. Poultry Science, v.78, n.8, p.1158-1169, 1999.

D'MELLO, J.P.F. Amino acids in animal nutrition. Wallingford: Cab International, 2003.513p.

FERKET, P.; OLIVEIRA, J.; GHANE, A. et al. Effect of in ovo feeding solution osmolality on hatching turkeys. In: INTERNATIONAL POULTRY SCIENTIFIC FORUM, 2005, Atlanta. Abstracts... Atlanta: Poultry Science Association, 2005a. p.28.

FERKET, P.; UNI, Z.; FOYE, O. Enhanced of pre- and post-hatch development of turkey by in ovo feeding. In: INTERNATIONAL POULTRY SCIENTIFIC FORUM, 2005, Atlanta. Abstracts... Atlanta: Poultry Science Association, 2005b. p.42.

FOYE, O.; FERKET, P.; UNI, Z. The effects of in ovo feeding of protein and beta-methyl-beta hidroxybutyrate (HMB) on nutrient digestion and absorption in neonatal turkey poults. In: INTERNATIONAL POULTRY SCIENTIFIC FORUM, 2005, Atlanta. Abstracts... Atlanta: Poultry Science Association, 2005. p.5.

GEYRA, A.; UNI, Z.; SKLAN, D. Enterocyte dynamics and mucosal development in the posthatch chick. Poultry Science, v.80, n.6, p.776-782, 2001.

GONZALES, E.; OLIVEIRA, A.S.; CRUZ, C.P. et al. In ovo supplementation of $25(\mathrm{OH}) \mathrm{D} 3$ to broiler embryos. In: EUROPEAN SYMPOSIUM ON POULTRY NUTRITION, 2003, Lillehammer. Proceedings... Lillehammer: Science Association, 2003. p.72-74.

GOMIDE JR., M.H.; STERZO, E.V.; PIRES, D.L. et al. Efeitos da injeção de ácido ascórbico in ovo sobre a densidade e integridade dos vilos intestinais de frangos fêmeas submetidos a jejum póseclosão. In: SIMPÓSIO INTERNACIONAL DE INICIAÇÃO CIENTÍFICA DA UNIVERSIDADE DE SÃO PAULO, 2003, Piracicaba. Anais... Piracicaba: Fundação da Escola Superior de Agricultura Luiz de Queiroz, 2003. (CD-ROM).

GUSTIN, P.C. Manejo dos pintos no incubatório, expedição, transporte e alojamento na granja. In: MACARI, M.; GONZALES, E. (Eds). Manejo da incubação. Campinas: Fundação APINCO de Ciência e Tecnologia Avícolas, 2003. p.200-266.

HARVEY, S.; JOHNSON, C.D.M.; SANDERS, E.J. Growth hormone in neural tissue of the chick embryo. Journal of Endocrinology, v.169, n.3, p.487-496, 2001.

INGRAN, D.R.; DEAO, C.E.; FLOYD, S.A. et al. Effects of in ovo injection of glucose on subsequent body weight. Poultry Science, v.76, p.51, 1997 (suppl.).

IPEK, A.; SAHAN, U.; YILMAZ, B. The effects of in ovo ascorbic acid and glucose injection in broiler breeder eggs on hatchability and chick weight. Archiv für Geflügelkunde, v.68, n.3, p.132-135, 2004.

JEPSON, M.M.; BATES, P.C.; BROADBENT, P. et al. Relationship between glutamine concentration and protein synthesis in rat skeletal muscle. American Journal of Physiology, v.255, n.2, p.166-172, 1988.

JOHRI, T.S. Feasibility of in ovo amino acid injection for embryonic growth and optimizing total and digestible amino acid requirements for meat production and immunocompetence of broiler chickens. Poultry nutrition in India. Disponível em: http://www.fao.org Acesso em: 20/08/04.

KLASING, K.C. Comparative avian nutrition. Wallingford: Cab International, 1998. 136p.

LATOUR, M.; PEEBLES, E.D.; DOYLE, S.M. et al. Broiler breeder age and dietary fat influence the yolk fatty acid profiles of fresh eggs and newly hatched chicks. Poultry Science, v.77, n.1, p.47-53, 1998.

LEITÃO, R.A.; LENDRO, N.S.M.; PEDROSO, A.A. et al. Efeito da suplementação de glicose in ovo sobre o desempenho inicial de pintos de corte. Revista Brasileira de Ciência Avícola, v. 7, n. suplemento, p.69, 2005.

LONGO, F.A. Avaliação de fontes de carboidrato e proteína e sua utilização na dieta pré-inicial de frangos de corte. Piracicaba: Universidade de São Paulo, 2004. 110p. Tese (Doutorado em Ciência Animal e Pastagens) - Universidade de São Paulo, 2004.

LONGO, F.A; MENTEN, J.F.M.; PEDROSO, A.A. et al. Diferentes fontes de carboidrato na dieta pré-inicial de frangos de corte. Revista Brasileira de Zootecnia, v.34, n.1, p.112-122, 2005.

MAIORKA, A. Efeitos da idade a matriz, do jejum, da energia da ração e da glutamina sobre o desenvolvimento da mucosa intestinal e atividade enzimática do pâncreas de pintos de corte. Jaboticabal: Universidade Estadual Paulista, 2002. 103p. Tese (Doutorado em Zootecnia) - Universidade Estadual Paulista, 2002.

MATARESE, L.E.; SEIDNER, D.L.; STEIGER, E. Growth hormone, glutamine, and modified diet for intestinal adaptation. Journal of American Diet Association, v.104, n. 8, p.1265-1272, 2004.

NOY, Y; SKLAN, D. Yolk utilization in the newly hatched poult British Poultry Science, v.39, n.3, p. 446-451, 1998.

OHTA, Y.; TSUSHIMA, N.; KOIDE, K. et al. Effects of amino acid injection in broiler breeder eggs on embryonic growth and hatchability of chicks. Poultry Science, v.78, n.11, p.14931498, 1999.

OHTA, Y.; KIDD, M.T. Optimum site for in ovo amino acid injection in broiler breeder eggs. Poultry Science, v.80, n.10, p.1425-1429, 2001.

OHTA, Y.; KIDD, M.T.; ISHIBASHI, T. Embryos growth and amino acid concentration profiles of broiler breeder eggs, embryos and chicks after in ovo administration of amino acids. Poultry Science, v.80, n.10, p.1430-1436, 2001.

OHTA, Y.; YOSHIDA, T.; TSUSHIMA, N. Comparison between broilers and layers for growth and protein use by embryos. Poultry Science, v.83, n.5, p.783-787, 2004.

POWELL, K.A.; DEANS, E.A.; SPEAKE, B.K. Fatty acid etherification in the yolk sac membrane of the avian embryo. Journal of Comparative Physiology B, v.174, n.2, p.163-168, 2004.

RAY, E.C.; AVISSAR, N.E.; VUKCEVIC, D. et al. Growth hormone and epidermal growth factor together enhance amino acid transport systems B and A is Remnant small intestine after massive enterectomy. Journal of Surgical Research, v.115, n.1, p.164-170, 2003.

ROSTAGNO, H.S.; ALBINO, L.F.T.; DONZELE, J.L. et al.Tabelas brasileiras para aves e suínos: composição de alimentos e exigências nutricionais. 1.ed. Viçosa, MG: Universidade Federal de Viçosa, 2000. 141p.

STATISTICAL ANALYSIS SYSTEM - SAS. User's guide. Version 6.11. Cary: 1998. 634p.

SKLAN, D.; GEYRA, A.; TAKO, E. et al. Ontogeny of brush border carbohydrate digestion and uptake in the chick. British Journal of Nutrition, v.89, n.6, p.747-753, 2003. 
SKLAN, D. Fat and carbohydrate use in posthatch chicks.Poultry Science, v.82, n.1, p.117-122, 2003

SMIRNOV, A.; SKLAN, D.; UNI, Z. Mucin dynamics in the chicks small intestine are altered by starvation. Journal of Nutrition, v.134, n.4, p.736-742, 2004.

UNI, Z. Bases fisiológicas e molecular gastrintestinal durante o período pré e pós eclosão. In: CONFERÊNCIA APINCO DE CIÊNCIA E TECNOLOGIA AVÍCOLAS, 2001, Campinas. Anais... Campinas: Fundação APINCO de Ciência e Tecnologia Avícolas, 2001. p.109-116.

UNI, Z. Methods for early nutrition and their potential. In: EUROPEAN SYMPOSIUM OF POULTRY NUTRITION, 2003, Lillehammer. Proceedings... Lillehammer: World Poultry Science Association, 2003. p.254-260.
UNI, Z; FERKET, P.R.; TAKO, E. et al. In ovo feeding improves energy status of late-term chicken embryos.Poultry Science, v.84, n.5, p.764-770, 2005.

VIEIRA, S.L.; MORAN JR, E.T. Eggs and chicks from broiler breeders of extremely different age. Journal of Applied Poultry Research, v.7, n.2, p.372-376, 1998.

WELBORNE, T.C. Increased plasma bicarbonate and growth hormone after an oral glutamine load. American Journal of Clinical Nutrition, v.61, n.5, p.1058-1061, 1995.

Recebido: 10/08/05 Aprovado: 31/05/06 